Proc. of the Seventh Intl. Conf. on Advances in Social Science, Economics and Management Study - SEM 2018

Copyright (C) Institute of Research Engineers and Doctors, USA .All rights reserved.

ISBN: 978-1-63248-164-1 DOI : 10.15224/978-1-63248-164-1-03

"The anticipated impact of the Prospective integrated casino resort on the tourism industry of Cyprus"

Ria Nicoletti Morphitou (University of Nicosia)

Cyprus

Marlen Demetriou (University of Nicosia)

Cyprus

Contact Person: Tel. +35722841707 


\section{The anticipated impact of the Prospective integrated casino resort on the tourism industry of Cyprus"}

\section{Ria Nicoletti Morphitou\& Marlen Demetriou}

\begin{abstract}
The purpose of this research paper is to explore mainly the impact of the prospective integrated casino resort on the tourism industry of the Republic of Cyprus. The orientation of the report is diagnostic from a marketing perspective in order to identify its compatibility with the existing tourist markets in Cyprus. It also explored salient themes of the theory on integrated casino resorts in Las Vegas and Macau, and more precisely the emphasis given on: the service environment, the employee service, the brand, and the corporate social responsibility. The study takes a qualitative approach where a more in-depth evaluation of existing literature and in depth interviews with executives from the Cyprus Tourist Organization and the Ministry of Tourism have taken place.
\end{abstract}

Key words: Casino, tourism, consumer behaviour

\section{Introduction}

Cyprus is a popular tourist destination located in the Eastern Mediterranean Sea, which offers an ever-enticing tourist product, namely, warm weather, sunshine throughout most of the year, beautiful beaches and clear blue waters. Its beaches gained international prominence, having been awarded with the title of the "Cleanest Bathing Waters in Europe" and tens of Blue Flags. Its tourism industry, which is the cornerstone of its GDP, has also been awarded multiple occasions, among others, with the Destinations Global Top 100, and with the Totem Tourism and Green Destination titles (KPMG, 2017). The anticipated launch of the integrated resort casino in the coming years appears as an interesting proposition that could solve many problems and provides a positive effect on the tourism industry and the economy of the island.
An integrated resort casino (IRC) offers gaming and non-gaming services like hotel accommodation, entertainment venues, conference facilities, a network of restaurants and shopping outlets, and other recreational facilities like wellness centers and golf courses (PwC London Gaming Centre of Excellence, 2016).

\section{Literature Review}

\section{A. IRCs and the "Experience Economy"}

What differentiates IRCs from other casino properties is the overall experience they offer (lo \& Wan, 2017). Tourism literature on casino resorts point to the importance of providing an all-around positive "hedonic experience" to visitors (lo \& Wan, 2017, p.1). In other words, customer satisfaction is not determined only by the value of the product or service e.g. hotel accommodation, but by the quality and quantity of the experiences offered to the visitor, including both the gaming and the nongaming aspect. IRCs belong to "experience economies" (Wong \& Wu, 2013, p.215) in which the aim is to create memorable and special experiences in an environment with many businesses that aim to attract tourists who are interested in both gaming and non-gaming activities (lo \& Wan, 2017). lo and Wan (2017) suggest that the customer satisfaction of tourists and their emotional attachment to an IRC is estimated by the provision of experience that appeals to their emotional and functional needs that lie beyond the conventional provision of quality and value such as exceptional accommodation services. There is a consensus in the literature on casino resorts that casino properties are not just places where business transactions take place, but also are an integral part of the tourists' experience.

PwC (2016) and Horner and Swarbrooke (2016) concur that vacation is the main reason why people visit IRC resorts in Las Vegas and not solely gambling. Thus, a holistic approach needs to be taken into consideration in order to understand and provide an overall positive experience for the IRC customer. Wong \& Wu (2013) suggested that such an approach entails appealing to a collection of "experiential attributes" (p.221) that affects 
customer intrinsically. The authors contended that an improvement on one category, for example, an increase in the value of the product or service might lead to positive but isolated customer behavior outcomes because value is just a component of the customers' evaluation of the resort.

Likewise, Pearce, Wu, De Carlo and Rossi (2013) suggested a five-component framework for the analysis of selling experience to tourists in integrated resorts. The framework consists of fives aspects; the behavioral aspect (preference of tourist activities), the sensory aspect (how appealing the site and the weather is to the five senses), the social aspect (how much contribution travel companions, other tourists, local service staff and vendors have on the on-site enjoyment of the tourist), the cognitive aspect (understanding how the tourists evaluate their experience), the affective aspect (identifying the evoked positive emotions of the tourists).

Wong and Rosenbaum (2012) asserted that the service environment and the hedonic non-gaming aspects like shopping, entertainment and dining are offerings that international tourists look for in gaming destinations.

In light of this, it is important to consider how Horner and Swarbrooke (2016) describe the "hedonistic tourist" (p.190). According to the authors, this segment is mainly formed by younger people who, along with the seeking of pleasureinducing activities, they require the sun, sea, sand and party components. They also consider the fashion component, which implies that the popularity of a resort is highly susceptible to the perception of a consumer regarding the nightlife it offers. This includes the live shows, which are major sources of attraction in IRCs. Thus, a timeless favourable reputation for its perceived nightlife is a requirement for the Cypriot IRC. The element of novelty in the offerings of an IRC becomes even more important when considering it in light of the Kano model of customer needs (Antonaras, 2016), which suggests that exciters/delighters are those unexpected and innovative features that lead to higher perception of quality among customers, which is a determinant of customer satisfaction.
Since customer satisfaction is an important factor for achieving competitive advantage, it is important to consider that in order to retain a strong competitive advantage; the IRC must look for consistently upgrading the experiential package it offers. It also indicates that the businesses constituting the IRC must offer the latest products and services of the market, and the IRC to be perceived as a market leader and not only remain one theoretically, given its first mover advantage.

\section{B. Gambling and Non-Gambling Motivations}

Cotte (1997, as cited in Wong \&Rosebaum, 2012) suggested three motives that reinforce people to gamble: the economic motive which includes the financial rewards, the symbolic motive i.e. the sense of independence, the sense of control over destiny (perception of luck), and an escape from the monotony of daily life, and the hedonic motive which includes all those aspects pertaining to entertainment and pleasure that can also enhance self-esteem and self-image (Wong \& Wu, 2013). In line with the theory of the experience economy, the author further contends that there is a convergence of the practice of gambling into an "experiential consumption process" in which the consumer further demands novelty among other hedonic offerings. This is in line with the description of the hedonistic tourist described before who expects novel and various hedonic offerings of the IRC.

While gambling is one of the primary reasons people visit an IRC, the situation is more complex when it comes to visitors with children.

\section{High-roller Individuals}

With the exception of problematic gamblers those who have an urge to gamble repeatedly despite incurring negative consequences - like consistent financial losses - the consumers who will travel to Cyprus and gamble need to have sufficient disposable income that can afford them to gamble, never mind enjoying other services offered by an IRC. This is supported by findings that show income elasticity of international tourism demand is positive and above one and it is therefore a luxury good (Nouri \&Soltani, 2017). The consumer who has sufficient disposable income to place bets that are much bigger than what the average consumer 
would wager is known as a high-roller. This income cluster is sought-after by IRCs since high-rollers can contribute up to half of gaming revenues (PwC London Gaming Centre of Excellence, 2016). According to consumer behavior theory, social classes ranging from routine manual occupations to higher managerial occupations can help determine those who will more likely belong to the VIP segment of the IRC market (Papasolomou, 2015), but also those who will fall in the much larger gambling-for-leisure segment. However, when it comes to casino gambling, a high-roller will most likely be a millionaire or even a billionaire.

Some of the most important markets in the tourism industry of Cyprus, namely, UK, Russia, Germany, and Israel, are homes of billionaires (Wealth-X, 2017) and millionaires (Capgemini, 2017). Although Lebanon, France, the UAE, Switzerland and Norway are not in the cluster of countries that send over 100,000 tourists per year, they remain important for a number of reasons. They are prioritized as target markets in the Cyprus Tourism Strategy 2030 (Ministry of Energy, Commerce, Industry and Tourism, 2017), each one sends over 10,000 tourists per year (Statistical Service of the Republic of Cyprus, 2017), UAE, Switzerland, Norway and France are homes of millionaires and billionaires (Wealth X, 2017; Capgemini 2017). The Lebanese display an affinity for gambling in the occupied area of Cyprus, and the French the highest affinity for gambling in Europe (European Casino Association, 2017).

Finally, the forecasted growth of Ultra-High-NetWorth-Individuals in the Middle East is at $40 \%$ and in the former USSR at 32\% (PwC London Gaming Centre of Excellence, 2016), signifying the potential of the IRC attracting high-roller individuals from these regions.

According to PwC (2016), the provision of positive experiences for High-Net-Worth-Individuals could signify that the mass market will have positive experiences too. Wong and $\mathrm{Wu}$ (2013) found that the higher income segment of an IRC market is inclined to draw conclusions about the resort based on its service environment and employee service. This gives reason to believe that the timeless good hospitality of the tourism industry in Cyprus (Nouri \&Soltani, 2017) will cater to this expectation. It is also reasonable to assume that setting a benchmark on these two pillars could be two driving forces for positive customer experience (PwC London Gaming Centre of Excellence, 2016), so this study attempts to explore whether the service environment and employee service of this IRC will have a substantial impact on the tourism industry of Cyprus.

\section{Special Interest Tourism (SIT)}

An operational definition for SIT can be the one given by Douglas, Douglas, and Derrett who said it is the "provision of customized leisure and recreational experiences driven by the specific expressed interest of individuals and groups" (2001, p.3, as cited in Koutra \& Karyopouli, 2013). The authors further contend that SIT involves rewarding, enriching, adventure and learning experiences for the tourists. The Cyprus Tourism Strategy 2030 (Ministry of Energy, Commerce, Industry and Tourism, 2017) asserts that Cyprus can offer a range of SIT products like trips exploring the culture, conference facilities for business travellers, and sports facilities for amateurs and professionals. In addition, the strategy mentions more SIT products that categorizes them as a second priority, for example, wellness facilities, sailing and yachting, golf courses and wedding venues.

Koutra and Karyopouli (2013) found that SIT products could attract tourists during the less popular winter months in Cyprus. An activity or special interest motivating someone to travel can be the "focus of the whole holiday, or a way to spend one or two days during a holiday" (Horner \& Swarbrooke, 2016, p.38). In light of this and the finding of Koutra and Karyopouli (2013), this study examines whether tourism products and services beyond those offered by the IRC will act as complementary sources of attraction that will increase the number of tourists who will visit the IRC.

\section{Research Approach}

An inductive approach was used throughout the study, with the exception of the analysis of the European market in the literature review, which followed a deductive approach to make inferences. Saunders, Lewis and Thornhill (2012) described an inductive approach as the process of collecting 
data, reviewing it and then identifying the ideas that need to be given emphasis in order to develop "a conceptual framework to guide subsequent work" (p. 549). The nature of this study was exploratory in that it sought to discover insights on several levels (markets, marketing mix, etc.) related to the topic of the IRC and examine its potential as a business proposition. Primary data was retrieved from face-to-face interviews.

\section{Discussion}

Undoubtedly, the expectations for this one of a kind project for Cyprus are set high, not only because of its exclusivity as the first and largest integrated resort casino of Europe, but also because of the impact it will have on one of the basic pillars of the economy of the island, namely, the tourism industry. For the first time in recent history, Cyprus has the biggest opportunity to overcome the barrier of seasonality by attracting tourists who have the propensity for high expenditures, and in particular, the business travelers. The high-quality/high-expenditure tourists targeted by the IRC is not only an ideal target market for the operators but for the sustainability of the economy of the island as well. In addition, the initial influx of these affluent groups of visitors is expected to stay stable because the offerings of this resort appeal to timeless demands, namely, gambling and participating in conferences.

The diversification of the current tourist product through the provision of gaming and conference facilities is a strategy that is expected to be implemented successfully, as these two sectors have not been developed by the tourism industry of the Republic of Cyprus but there is an established demand among its major markets including the UK, the EU, and the Middle-East. The stable and consistent demand for gambling in Europe is an indication that the IRC of Cyprus will be favored by Europeans, particularly the British. Sweden, Germany and Switzerland are also major markets of the tourism industry of Cyprus that send tourists to Cyprus who have high-expenditures, which is an ideal target market for the IRC. The other EU countries, taken together, comprise a big prospective market because each one sends a considerate number of tourists to Cyprus per year.
Although a large number of Chinese does not visit Cyprus, the IRC stands as a good proposition for attracting bigger numbers of Chinese, given the rising middle-class of China, and the affinity of the Chinese for travelling and gambling. The compatibility of the Russian tourist with what Cyprus currently offers as a tourist destination and with what it will offer after the launch of the IRC is ideal, so Russia will be a major market for the IRC. In addition, the suitable geographical position of Cyprus along with the favorable reputation of Europe as a tourist and business destination among non-Europeans and High-Net-Worth-Individuals can make this IRC even more prominent. On a similar note, the lack of effectiveness of the national marketing endeavors to attract tourists is not going to be a hindrance to the success of the IRC as its operators will undertake the marketing campaigns by collaborating with junkets whose specialty is to organize the trips of high-net-worth clientele to IRCs all over the world.

Furthermore, the domestic market will not be a major source of revenue for the IRC, mainly because of the small size of its population. Although special interest tourism in Cyprus including sports, cultural, rehabilitation and medical tourism is growing, it will not have a mediating role in attracting more tourists for the IRC. However, the development of infrastructure and businesses within the vicinity of the IRC will have a mediating role in catering to the needs of the visitors.

Despite the difficulties that the Cypriot economy still faces in the private sector, its tourism industry is growing and with adequate allocation of funds from the European Commission President's Investment Plan, the overall tourist package of Cyprus could be upgraded considerably by the time the IRC becomes operational. With the launch of the IRC, the hospitality industry of Cyprus is expected to improve, as the exceptional standards of the resort will compel hotels to upgrade their services. Although the IRC will have a great impact on the tourism industry of Cyprus, it should not be seen as a dangerous competitor because it will cater mainly to the needs of the gambler and the visitors partaking in conferences. Another positive impact of the IRC, beyond the financial one for the government, the creation of many jobs which will 
benefit the Cypriot economy, and the upgrade of the hospitality industry of Cyprus, is the advancement of the local economy which will happen through the development of infrastructure and businesses within its vicinity to cater to the needs of the visitors of the IRC.

Melco Resorts \& Entertainment Ltd., the company in which the brand of the IRC belongs to, is a multiawarded promising company from Asia that has the know-how to deliver what the customer wants, which is an overall experiential package. The commitment of the company to innovation will play a fundamental role in retaining the competitive advantage as the market leader of the region, given its first mover advantage. In addition, the CSR programs including the legal, economic, philanthropic and ethical dimensions are expected to be addressed sufficiently, but the consistent commitment to CSR programs like transparency among the stakeholders including the government and the national gaming authority, and the highcaliber level of internal operations will play a fundamental role for the success of this resort. We can argue that the consortium that will run the IRC is expected to perform well and be successful for at least the 15-year period it is licensed to operate as a monopoly in Cyprus.

\section{Limitations and Recommendations}

This study is constrained by a limitation associated with the inductive approach, namely, the exploration of all the relevant data, therefore the findings do not reflect all the advantages or disadvantages of the anticipated IRC of Cyprus. However, what has been clarified is that the gaming sector and the M.I.C.E. sector, particularly the business travelers travelling to attend conferences, will be the emerging sources of revenues for the IRC and the tourism industry of Cyprus. Thus, more extensive research on the consumer behavior of business travelers visiting Cyprus is strongly recommended. In addition, since the European demand for on-site casino gambling is crosssectional, a longitudinal study on the overall European demand for gambling including online gambling is recommended to re-evaluate the validity of the findings of this study. Finally, the mediating role of ground transport efficiency in satisfying the expected influx of tourists in Cyprus is also recommended.

\section{References}

1. Antonaras, A. (2016). Customer Focus. Presentation, University of Nicosia.

2. Horner, S., \&Swarbrooke, J. (2016). Consumer behaviour in tourism. Abingdon, Oxon: Routledge

3. Io, M., \& Wan, P. (2017). Relationships between Tourism Experiences and Place Attachment in the Context of Casino Resorts. Journal of Quality Assurance in Hospitality \& Tourism, 1-21. http://dx.doi.org/10.1080/1528008x.2017. 1314801

4. Koutra, C., \&Karyopouli, S. (2013). Cyprus' image-a sun and sea destination-as a detrimental factor to seasonal fluctuations. Exploration into motivational factors for holidaying in Cyprus. Journal of Travel \& Tourism Marketing, 30(7), 700-714. http://dx.doi.org/10.1080/10548408.2013. 827548

5. KPMG. (2017). Cyprus Tourism Market Report. KPMG. Retrieved from http://www.cyprusprofile.com/documents/ uploads/publications/cyprus-tourismmarket-report-fourth-edition.pdf

6. Melco Resorts \& Entertainment | Innovating Excitement for a New Age. (2017). Melcoresorts.com. Retrieved 12 November 2017, from http://www.melcoresorts.com/en/index.php?route=propertie $\underline{\mathrm{S}-\mathrm{SC}}$

7. Melco Resorts \& Entertainment |Innovating Excitement for a New Age. (2018). Melcoresorts.com. Retrieved 11 January 2018, from http://www.melcoresorts.com/en/index.php?route=propertie s-cod

8. Ministry of Energy, Commerce, Industry and Tourism, Republic of Cyprus (2017). Cyprus Tourism Strategy 2030 Executive Summary. THR 
AsesoresenTurismoHotelería y Recreación

S.A.

9. Nouri, B., \&Soltani, M. (2017). Forecasting

of Tourism Demand for Cyprus: Generalized Method of Moments. Journal of Applied

Economics And Business Research, 7(2), 83-

96. Retrieved from

http://www.aebrjournal.org/uploads/6/6/2 L2/6622240/joaebrjune2017 83 96.pdf

10. Pearce, P., Wu, M., De Carlo, M., \& Rossi, A. (2013). Contemporary experiences of

Chinese tourists in Italy: An on-site analysis

in Milan. Tourism Management

Perspectives, 7, 34-37.

http://dx.doi.org/10.1016/j.tmp.2013.04.00

1

11. PwC London Gaming Centre of Excellence.

(2016). Is Europe ready for Integrated

Resort Casinos? PwC. Retrieved from

https://www.pwc.com/gx/en/hospitality-

leisure/pdf/is-europe-ready-for-integrated-

resort-casinos.pdf

12. Saunders, M., Lewis, P., \& Thornhill, A.

(2012) Research methods for business

students ( $6^{\text {th }}$ ed.). Harlow, Essex, England:

Pearson Education Limited.

13. Wong, I., \& Rosenbaum, M. (2012). Beyond

Hardcore Gambling. Journal of Hospitality \&

Tourism Research, 36(1), 32-51.

http://dx.doi.org/10.1177/1096348010380

$\underline{600}$

14. Wong, I., \& Wu, J. (2013). Understanding

casino experiential attributes: An

application to market positioning.

International Journal of Hospitality

Management, 35, 214-224.

http://dx.doi.org/10.1016/j.ijhm.2013.06.0

$\underline{09}$

15. Wong, I., In Veronica Fong, H., \&Tingchi Liu, M. (2012). Understanding perceived casino service difference among casino players. International Journal of Contemporary Hospitality Management, 24(5), 753-773. http://dx.doi.org/10.1108/0959611121123 $\underline{7282}$ 